\title{
Macrolide resistance determinants among Streptococcus pneumoniae isolates from carriers in Central Greece
}

\author{
Ioanna N Grivea, Alexia Sourla, Eleni Ntokou, Denise C Chryssanthopoulou, Alexandra G Tsantouli \\ and George A Syrogiannopoulos ${ }^{*}$
}

\begin{abstract}
Background: We sought to characterize the temporal trends in nasopharyngeal carriage of macrolide-resistant pneumococci during a period with increased heptavalent pneumococcal conjugate vaccine (PCV7) coverage in Central Greece.

Methods: Streptococcus pneumoniae isolates were recovered from 2649 nasopharyngeal samples obtained from day-care center attendees in Central Greece during 2005-2009. A phenotypic and genotypic analysis of the isolates was performed, including the identification of macrolide resistance genes mef(A), subclasses mef(A) and mef(E), as well as erm(B).

Results: Of the 1105 typeable S. pneumoniae isolates, 265 (24\%) were macrolide-resistant; 22\% in 2005, 33.3\% in 2006, 23.7\% in 2007, and 20.5\% in 2009 ( $P=0.398)$. Among these macrolide-resistant pneumococci, 28.5\% possessed $\operatorname{erm}(\mathrm{B}), 24.3 \% \operatorname{erm}(\mathrm{B})+\operatorname{mef}(\mathrm{E}), 41.8 \% \operatorname{mef}(\mathrm{E})$, and $5.3 \% \operatorname{mef}(\mathrm{A})$. A mef gene as the sole resistance determinant was carried by $31 \%$ of macrolide-resistant isolates belonging to PCV7 serotypes and $75.8 \%$ of the non-PCV7 serotypes. Across the 4 annual surveillances, pneumococci carrying mef(A) gradually disappeared, whereas serotype $19 \mathrm{~F}$ isolates carrying both erm $(\mathrm{B})$ and $\operatorname{mef}(\mathrm{E})$ persisted without significant yearly fluctuations. Among isolates belonging to non-PCV7 serotypes, macrolide-resistance was observed in those of serotypes 6A, 19A, 10A, 15A, 15B/C, 35F, 35A, and 24F. In 2009, ie 5 years after the introduction of PCV7 in our country, 59\% of macrolide-resistant pneumococci belonged to non-PCV7 serotypes.

Conclusions: Across the study period, the annual frequency of macrolide-resistant isolates did not change significantly, but in 2009 a marked shift to non-PCV7 serotypes occurred. Overall, more than half of the macrolide-resistant isolates possessed erm(B) either alone or in combination with mef(E). erm(B) dominated among isolates belonging to PCV7 serotypes, but not among those of non-PCV7 serotypes.
\end{abstract}

\section{Background}

Streptococcus pneumoniae is a gram-positive bacterium commonly found in the human nasopharynx, in particular during early childhood [1,2]. In most individuals colonization is asymptomatic and does not evolve into disease [3,4]. In addition to the carriage state, S. pneumoniae is also a common human pathogen responsible for bacteremia, sepsis, and meningitis, as well as noninvasive

\footnotetext{
* Correspondence: syrogian@otenet.gr

Department of Pediatrics, University of Thessaly, School of Medicine, General University Hospital of Larissa, Biopolis, 41110 Larissa, Greece
}

disease, such as non-bacteremic pneumonia, otitis media, and sinusitis $[4,5]$.

Resistance to erythromycin and other macrolides is common in S. pneumoniae isolates recovered from carriers and patients [6-14]. The major mechanisms of macrolide resistance in S. pneumoniae are target modification and drug efflux [15]. The genetic determinant conferring macrolide resistance by target modification is mainly erm(B) [16]. The erm(B) gene methylates the peptidyl transferase center of $23 \mathrm{~S}$ rRNA, thereby conferring high-level resistance to 14-, 15- and 16-membered ring macrolides, lincosamides and streptogramin $\mathrm{B}\left(\mathrm{MLS}_{\mathrm{B}}\right.$ phenotype) [15]. 
The second macrolide resistance mechanism is an efflux pump system encoded by mef and an ATP-binding cassette protein encoded by the mel gene [17]. The efflux mechanism confers resistance to 14- and 15-member macrolides only (M phenotype) $[18,19]$. Two main variants of mef, mef(E) and mef(A), which are approximately $90 \%$ identical at the nucleotide level and have been assigned to the same class of macrolide resistance determinants, mef(A) [20], are found in S. pneumoniae $[21,22]$. These two genes are located on different genetic elements [22,23]. mef(A) is located on the defective transposon Tn1207.1 [24], or the closely related Tn1207.3 [25], whereas mef(E) on "mega" element $[17,26,27]$.

Greece has a high prevalence of antibiotic-resistant S. pneumoniae [28-30]. In our country, PCV7 became available in October 2004; it was officially introduced to children younger than 5 years of age in January 2006 and was reimbursed by $80 \%$ by the national health insurance system in June 2006. The aim of the present investigation was to study trends in carriage of macrolide-resistant pneumococci and to analyze their antibiotic susceptibility, serotypes, and macrolide resistance determinants. The isolates were collected in a prospective study conducted among day-care center attendees in Central Greece between 2005 and 2009.

\section{Methods}

\section{Study population}

Nasopharyngeal specimens were obtained from children attending day-care centers in Larissa, Volos, Trikala, and Karditsa, the 4 largest cities of Central Greece during an approximately three-month period in 2005, 2006, 2007, and 2009. In the annual surveillance, 1 sample was obtained from each child. Information regarding the participant's PCV7 vaccination status was collected. The research protocol was approved by the Ethics Committee of the General University Hospital of Larissa. Informed consent was obtained from one of the parents of each attendee.

\section{Vaccine schedule}

The Hellenic National Committee for Immunization Programs recommends PCV7 for routine administration as a 4-dose series for infants at 2, 4, 6, and 12 to 18 months of age. Catch-up immunization is recommended for all children up to 59 months of age [31].

\section{Laboratory procedures}

Specimens of nasopharyngeal secretions were obtained pernasally using sterile swabs on flexible shafts with calcium alginate fiber tips (Fisher Scientific, Pittsburgh, Philadelphia, USA). Swabs were placed in Amies transport medium (TGV, Sanofi Diagnostic Pasteur, Marne la Coquette, France) after sampling and were transferred to the Laboratory of the Division of Pediatric Infectious
Disease of the University of Thessaly, where isolation, identification and susceptibility testing of the S. pneumoniae isolates were performed as previously described [32]. The maximum delay between collection and cultivation was $7 \mathrm{~h}$.

The swabs were plated onto Columbia agar plates supplemented with $5 \%$ defibrinated horse blood, $10 \mu \mathrm{g}$ of colistin sulfate and $15 \mu \mathrm{g}$ of nalidixic acid per milliliter. The plates were incubated at $35^{\circ} \mathrm{C}$ in an atmosphere supplemented with $5 \% \mathrm{CO}_{2}$ for 24-72 h. Phenotypic characteristics (morphology and $\alpha$-hemolysis) were used for the presumptive identification of pneumococci. Pneumococcal identification was confirmed by optochin susceptibility and bile solubility assays. When suspected pneumococcal colonies with more than one morphology were observed, each type was purified for further testing.

Susceptibility testing to various antimicrobial agents representing different classes of antibiotics was performed on Mueller-Hinton agar supplemented with 5\% defibrinated horse blood, as follows. S. pneumoniae isolates were tested for susceptibility to erythromycin and clindamycin by both the disk diffusion method and the E-test method (AB Biodisk, Solna, Sweden). Isolates were screened for penicillin resistance using $1 \mu \mathrm{g}$ oxacillin disks. If the oxacillin inhibition zone was $<20 \mathrm{~mm}$, minimal inhibitory concentration (MIC) to penicillin was determined by the E-test method. Susceptibility to quinolones was determined by the E-test method. Isolates were tested with levofloxacin except for isolates recovered in 2005 that were tested with ciprofloxacin. Finally, susceptibility to chloramphenicol, tetracycline, and trimethoprimsulfamethoxazole (TMP-SMZ) was determined by the disk diffusion method. For susceptibility testing, plates with the antibiotic disks and E-test strips were incubated in $5 \% \mathrm{CO}_{2}$. The susceptibility breakpoints of the Clinical and Laboratory Standards Institute (CLSI) [33] and the European Committee on Antimicrobial Testing (EUCAST) [34] were used to classify organisms as susceptible, intermediate or resistant to the studied antibiotics. The oral penicillin $\mathrm{V}$ susceptibility breakpoints of CLSI were applied since in pediatric infections the treatment is mainly oral: $\leq 0.06 \mu \mathrm{g} / \mathrm{ml}$, susceptible; $0.12-$ $1 \mu \mathrm{g} / \mathrm{ml}$, intermediate; and $\geq 2 \mu \mathrm{g} / \mathrm{ml}$, resistant. The benzylpenicillin susceptibility breakpoints of EUCAST for infections other than meningitis were used: $\leq 0.06 \mu \mathrm{g} / \mathrm{ml}$, susceptible; $0.12-2 \mu \mathrm{g} / \mathrm{ml}$, intermediate; and $>2 \mu \mathrm{g} / \mathrm{ml}$, resistant. Pneumococci were defined as resistant to ciprofloxacin if their ciprofloxacin MICs were $\geq 4 \mu \mathrm{g} / \mathrm{ml}$. An isolate was defined as multidrug resistant (MDR) when it was resistant to $\geq 3$ antibiotic classes. Penicillins, cephalosporins, and carbapenems were considered a single class.

The macrolide resistance phenotypes were determined on the basis of the pattern of susceptibility to erythromycin 
and clindamycin and confirmed by the double disk diffusion test using erythromycin and clindamycin disks (BBL, Cockeysville, MD). Specifically, $15 \mu \mathrm{g}$ erythromycin and $2 \mu \mathrm{g}$ clindamycin disks were placed $16 \mathrm{~mm}$ apart. Induction was present when the zone of inhibition around the clindamycin disk was blunted on the side next to the erythromycin disk.

\section{Detection and analysis of the erm(B) and mef genes}

Bacterial DNA was extracted by using the QIAamp DNA Mini kit (QIAGEN, Hilden, Germany). The presence of macrolide resistance genes was detected by PCR as described previously [35]. In summary, we amplified the genes by PCR and analyzed the amplified DNA products by agarose gel electrophoresis. For erm(B) we used the primer pair 5'-CGA GTG AAA AAG TAC TCA ACC-3' and 5'-GGC GTG TTT CAT TGC TTG ATG-3' [36] and for mef gene the primer pair 5'-GCGTTTAAGATAAGCTGGCA-3' and 5'-CCTGCACCATTTGCTCCTAC-3' [22]. In order to discriminate between mef(A), subclasses mef(A) and mef(E), PCR restriction fragment length polymorphism analysis was performed, as suggested by Oster et al. [21]. The 1743-bp PCR product was digested with the BamHI or the DraI restriction enzyme. In mef(A) there is one BamHI site, so restriction generates two fragments of 1,340 and $403 \mathrm{bp}$, while in $m e f(\mathrm{E})$ there are no BamHI restriction sites. Restriction of mef(A) with DraI yields two fragements of 1,493 and $250 \mathrm{bp}$, respectively, while restriction of $m e f(\mathrm{E})$ yields three fragments of 782, 711, and $250 \mathrm{bp}$.

\section{Capsule serotyping}

Serotype determination of pneumococci, including serotype 6C, was performed at our Laboratory in Larissa by using Pneumotest-Latex and by the capsular swelling method using pneumococcal type/group and/or factor antisera from Statens Serum Institut (SSI, Copenhagen, Denmark). We followed the SSI guidelines for serotyping.

\section{Statistical analysis}

An attendee was defined as age-appropriately vaccinated if at sampling the child had received all the PCV7 doses recommended for the age at initiation of immunization [37]. A dose of PCV7 vaccine was counted if it had been received at least 30 days before the sampling date. Pneumococcal isolates were classified as PCV7 serotypes, non-PCV7 serotypes and nontypeable.

To assess the 4 groups of attendees enrolled during the 2005, 2006, 2007, and 2009 surveillance, categorical parameters were compared using the $\chi^{2}$ for trend. For the assessment of 2 groups, categorical parameters were compared using 2-sided Fisher exact test. The statistical analysis was performed using SPSS version 13.0. An effect was considered significant when $P<0.05$.

\section{Results}

\section{Population and samples}

Between February 28, 2005 and May 19, 2009, cultures were obtained from 2649 children aged 13 to 76 months (median age: 48 months). There were no children younger than 13 months old attending the studied day-care centers. The characteristics of children at the time of sampling are presented in Table 1. Description of the day-care centers has been published previously $[8,30]$. Of the 2649 children, 1196 (45.1\%) were identified as carriers of S. pneumoniae. Forty-six attendees carried two different pneumococcal isolates. Of the totally 1242 pneumococcal isolates, 1105 (89\%) were typeable. The present analysis was based on this collection of typeable isolates.

\section{Carriage of macrolide-resistant pneumococci}

From 2005 to 2009, 265 (24\%) of the 1105 typeable $S$. pneumoniae isolates were macrolide-resistant. Across the 4 surveillance periods, the proportion of macrolideresistant isolates did not change significantly. Specifically, their frequencies were $22 \%$ (77 of 350) in 2005, $33.3 \%$ (64 of 192) in 2006, 23.7\% (63 of 266) in 2007, and $20.5 \%$ (61 of 297) in 2009 ( $P=0.398)$. However, across the 4 sampling periods a significant decrease was noted in macrolide-resistant isolates belonging to PCV7 serotypes (from $17.4 \%$ to $26 \%, 12 \%$ and $8.4 \% ; P<0.001$ ) and a significant increase in the proportion of macrolide-resistant isolates belonging to non-PCV7 serotypes (from $4.6 \%$ to 7.3\%, 11.7\% and 12.1\%; $P<0.001$ ) (Figure 1).

Among macrolide-resistant pneumococci, the proportion of isolates belonging to non-PCV7 serotypes was $20.8 \%$ (16 of 77 ) in 2005, 21.9\% (14 of 64) in 2006, $49.2 \%$ (31 of 63) in 2007, and 59\% (36 of 61) in $2009(P<0.001)$.

During the first 2 annual surveillances, PCV7 serotypes 19F, 23F, 14, and 6B accounted for 60 (77.9\%) of the 77 macrolide-resistant isolates in 2005 and 50 (78.1\%) of the 64 in 2006. In contrast, during the 2009 surveillance, it was non-PCV7 serotypes 6A, 19A, 15A, and 15B/C that accounted for $33(54.1 \%)$ of the 61 macrolide-resistant pneumococci.

\section{Macrolide resistance determinants, phenotypes, and co-resistance}

Of the 265 macrolide-resistant pneumococci, 263 were studied for the presence of macrolide resistance determinants (Table 2). Seventy-five (28.5\%) carried the $\operatorname{erm}(\mathrm{B})$ gene, $64(24.3 \%)$ the $\operatorname{erm}(\mathrm{B})+\operatorname{mef}(\mathrm{E})$ genes, $110(41.8 \%)$ $m e f(\mathrm{E})$, and 14 (5.3\%) mef(A) (Table 2). All mef(A)- or mef(E)-positive $S$. pneumoniae isolates exhibited the M-phenotype. All erm(B)- and dual erm(B)+mef(E)-positive isolates showed the constitutive $\mathrm{MLS}_{\mathrm{B}}$ phenotype.

MICs to erythromycin of mef(A)-positive isolates ranged from 8 to $64 \mu \mathrm{g} / \mathrm{ml}\left(\mathrm{MIC}_{50}=32 \mu \mathrm{g} / \mathrm{ml} ; \mathrm{MIC}_{90}=64 \mu \mathrm{g} / \mathrm{ml}\right)$, mef(E)-positive from 1 to $64 \mu \mathrm{g} / \mathrm{ml} \quad\left(\mathrm{MIC}_{50}=4 \mu \mathrm{g} / \mathrm{ml}\right.$; 
Table 1 Characteristics of children at the time of enrollment $(\mathrm{N}=2649)$

\begin{tabular}{|c|c|c|c|c|c|}
\hline \multirow[t]{2}{*}{ Characteristic } & \multicolumn{4}{|c|}{ Year of surveillance } & \multirow[t]{2}{*}{$P$} \\
\hline & 2005 & 2006 & 2007 & 2009 & \\
\hline Time-period of enrollment & February 28 to June 7 & February 2 to April 13 & February 26 to May 17 & February 24 to May 19 & \\
\hline $\begin{array}{l}\text { PCV7 in the National Immunization } \\
\text { Program }\end{array}$ & - & + & + & + & \\
\hline PCV7 reimbursed & - & - & + & + & \\
\hline No. of enrolled children & 769 & 494 & 566 & 820 & \\
\hline Age, median (range), months & $49(15-76)$ & $46.5(13-70)$ & $46(13-73)$ & $48(14-72)$ & - \\
\hline Male gender & $417(54.2)^{a}$ & $248(50.2)$ & $297(52.5)$ & $427(52.1)$ & 0.529 \\
\hline Antibiotic use in the preceding 3 months & $433 / 764^{b}(56.7)$ & 260/489 (53.2) & $284 / 566(50.2)$ & $459 / 818(56.1)$ & 0.647 \\
\hline Vaccinated with $\geq 1$ dose of PCV7 & $99(12.9)$ & $161(32.6)$ & $397(70.1)$ & $783(95.5)$ & $<0.001$ \\
\hline Age-appropriately vaccinated & $92(12)$ & $150(30.4)$ & $351(62)$ & $668(81.5)$ & $<0.001$ \\
\hline \multicolumn{6}{|l|}{ Streptococcus pneumoniae carriage } \\
\hline \multicolumn{6}{|l|}{ per age-group, months } \\
\hline $13-23$ & $12 / 21(57.1)$ & $11 / 22(50)$ & 18/26 (69.2) & 13/18 (72.2) & 0.176 \\
\hline $24-35$ & $74 / 121(61.2)$ & $34 / 69(49.3)$ & $50 / 99(50.5)$ & $43 / 100(43)$ & 0.01 \\
\hline $36-47$ & 130/231 (56.3) & $78 / 185(42.2)$ & $84 / 183(45.9)$ & $118 / 279(42.3)$ & 0.006 \\
\hline $48-59$ & $101 / 240(42.1)$ & 70/188 (37.2) & 109/208 (52.4) & 132/349 (37.8) & 0.721 \\
\hline$\geq 60$ & $53 / 156(34)$ & 13/30 (43.3) & $25 / 50(50)$ & 28/74 (37.8) & 0.273 \\
\hline Overall & $370(48.1)$ & $206(41.7)$ & $286(50.5)$ & $334(40.7)$ & 0.036 \\
\hline
\end{tabular}

${ }^{a}$ Number in parentheses is percent, unless otherwise indicated.

${ }^{\mathrm{b}}$ The denominator indicates the number of children with available information on recent antibiotic use.

$\left.\mathrm{MIC}_{90}=8 \mu \mathrm{g} / \mathrm{ml}\right)$, erm(B)-positive from 4 to $256 \mu \mathrm{g} / \mathrm{ml}$ $\left(\mathrm{MIC}_{50}=256 \mu \mathrm{g} / \mathrm{ml} ; \quad \mathrm{MIC}_{90}=256 \mu \mathrm{g} / \mathrm{ml}\right)$, and dual $\operatorname{erm}(\mathrm{B})+m e f(\mathrm{E})$-positive was $256 \mu \mathrm{g} / \mathrm{ml}\left(\mathrm{MIC}_{90}=256 \mu \mathrm{g} / \mathrm{ml}\right)$.

A significant decline in $\operatorname{mef}(\mathrm{A})$ isolates was noted across the study period (Figure 2). Specifically, mef(A)-positive pneumococci of PCV7 serotypes accounted for $10.4 \%$ of the macrolide-resistant isolates in 2005, 1.6\% in 2006, and $0 \%$ in 2007 and $2009(P<0.001)$, whereas mef(A)-positive isolates of non-PCV7 serotypes accounted for $0 \%$ of the macrolide-resistant isolates

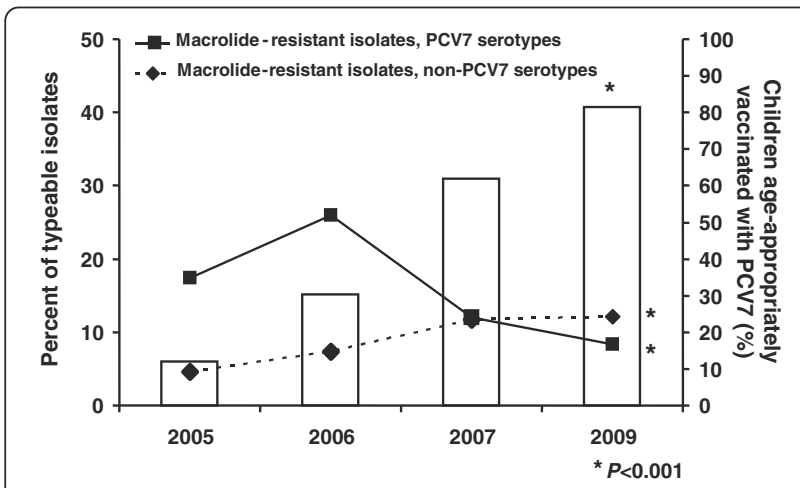

Figure 1 Serotype distribution of macrolide-resistant nasopharyngeal pneumococcal isolates and percentage of attendees age-appropriately vaccinated with PCV7 at the time of surveillance. in 2005, 4.7\% in 2006, 3.2\% in 2007, and $0 \%$ in 2009 $(P=0.993)$ (Figure 3).

Initially, the mef(E) gene was common among isolates of PCV7 serotypes, but since 2007 its frequency is higher

Table 2 Macrolide resistance determinant according to the serotype

\begin{tabular}{|c|c|c|c|c|c|}
\hline \multirow[t]{2}{*}{ Serotype } & \multirow{2}{*}{$\begin{array}{c}\text { No. of } \\
\text { isolates }\end{array}$} & \multicolumn{4}{|c|}{ Macrolide resistance determinant } \\
\hline & & erm(B) & $\operatorname{erm}(\mathrm{B})+m e f(\mathrm{E})$ & $m e f(E)$ & $\operatorname{mef}(\mathrm{A})$ \\
\hline $6 \mathrm{~A}$ & 69 & 0 & 0 & $64(92.8)$ & $5(7.2)$ \\
\hline $6 \mathrm{~B}$ & 12 & $11(91.7)^{a}$ & 0 & $1(8.3)$ & 0 \\
\hline $9 \mathrm{~V}$ & 1 & 0 & 0 & $1(100)$ & 0 \\
\hline $10 \mathrm{~A}$ & 5 & $5(100)$ & 0 & 0 & 0 \\
\hline 14 & 17 & $8(47.1)$ & 0 & 0 & $9(52.9)$ \\
\hline $15 \mathrm{~A}$ & 3 & $3(100)$ & 0 & 0 & 0 \\
\hline $15 B$ & 3 & $3(100)$ & 0 & 0 & 0 \\
\hline $15 C$ & 1 & $1(100)$ & 0 & 0 & 0 \\
\hline $19 A$ & 8 & 7 (87.5) & 0 & $1(12.5)$ & 0 \\
\hline $19 F$ & 108 & $3(2.8)$ & $64(59.3)$ & $41(38)$ & 0 \\
\hline $23 F$ & 30 & $30(100)$ & 0 & 0 & 0 \\
\hline $24 \mathrm{~F}$ & 1 & $1(100)$ & 0 & 0 & 0 \\
\hline $35 \mathrm{~A}$ & 2 & 0 & 0 & $2(100)$ & 0 \\
\hline $35 F$ & 3 & $3(100)$ & 0 & 0 & 0 \\
\hline
\end{tabular}

a Number in parentheses, percent. 


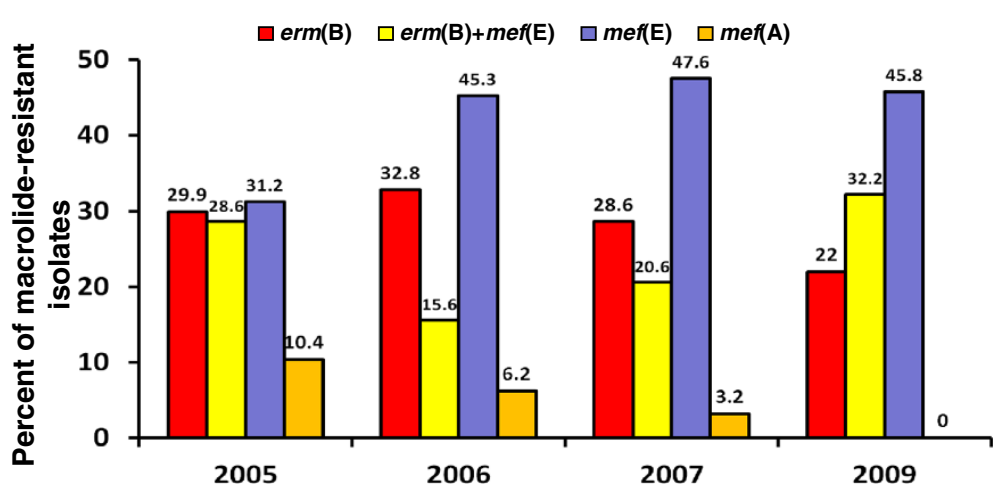

Figure 2 Frequencies of macrolide resistance determinants according to the year of surveillance.

among pneumococci of non-PCV7 ones (Figure 3). Specifically, mef(E)-positive isolates belonging to PCV7 serotypes accounted for $19.5 \%$ of the macrolide-resistant isolates in $2005,28.1 \%$ in $2006,6.3 \%$ in 2007 , and $10.2 \%$ in $2009(P=0.018)$, while $m e f(\mathrm{E})$-positive pneumococci belonging to non-PCV7 serotypes accounted for $11.7 \%$ of the macrolide-resistant isolates in $2005,17.2 \%$ in 2006 , $41.3 \%$ in 2007 , and $35.6 \%$ in $2009(P<0.001)$.

The $\operatorname{erm}(\mathrm{B})$ gene was common initially, from 2005 through 2007, among isolates belonging to PCV7 serotypes and in 2009 among those of non-PCV7 serotypes (Figure 3). Specifically, erm(B)-positive isolates belonging to PCV7 serotypes accounted for $20.8 \%$ of the macrolideresistant isolates in 2005, 32.8\% in 2006, 23.8\% in 2007, and $0 \%$ in $2009(P=0.003)$, while $\operatorname{erm}(\mathrm{B})$-positive isolates of non-PCV7 serotypes accounted for $9.1 \%$ of the macrolideresistant pneumococci in $2005,0 \%$ in $2006,4.8 \%$ in 2007 , and $22 \%$ in $2009(P=0.013)$.

The $\operatorname{erm}(\mathrm{B})+m e f(\mathrm{E})$-positive isolates belonged to serotype 19F (Table 2) and accounted for $28.6 \%$ of the macrolideresistant isolates in $2005,15.6 \%$ in $2006,20.6 \%$ in 2007 , and $32.2 \%$ in $2009(P=0.638)$ (Figure 4$)$.
Among the macrolide-resistant pneumococcal isolates recovered in 2005 and 2006, 53.9\% carried the erm(B) gene alone or in combination with $m e f(\mathrm{E})$. In 2009, $54.2 \%$ of the macrolide-resistant isolates possessed $\operatorname{erm}(\mathrm{B})$ alone or in combination with $m e f(\mathrm{E})$ (Figure 2).

Co-resistance rates among the 263 isolates with molecular evaluation are presented in Table 3. According to both CLSI and EUCAST breakpoints, nonsusceptibility to one or more other antimicrobial agents was found in $248(94.3 \%)$ of the 263 erythromycin-resistant isolates, constituting 16 different resistance patterns. Of these 248 isolates, $92.3 \%$ were nonsusceptible to penicillin, $70.2 \%$ (CLSI breakpoints) and 68.5\% (EUCAST breakpoints) to TMP-SMZ, $63.7 \%$ to tetracycline, $56 \%$ to clindamycin and $16.9 \%$ to chloramphenicol.

Multidrug-resistance was significantly more frequent among isolates carrying erm(B), either alone or in combination with $m e f(\mathrm{E})$, than among isolates harboring $m e f(\mathrm{E})$ or mef(A) alone $(P<0.001)$ (Table 3$)$. Pneumococci possessing $\operatorname{erm}(\mathrm{B})$ expressed a total of 11 different resistance patterns. Macrolide-resistant serotype 14 isolates harboring $\operatorname{erm}(\mathrm{B})$ and exhibiting penicillin nonsusceptibility

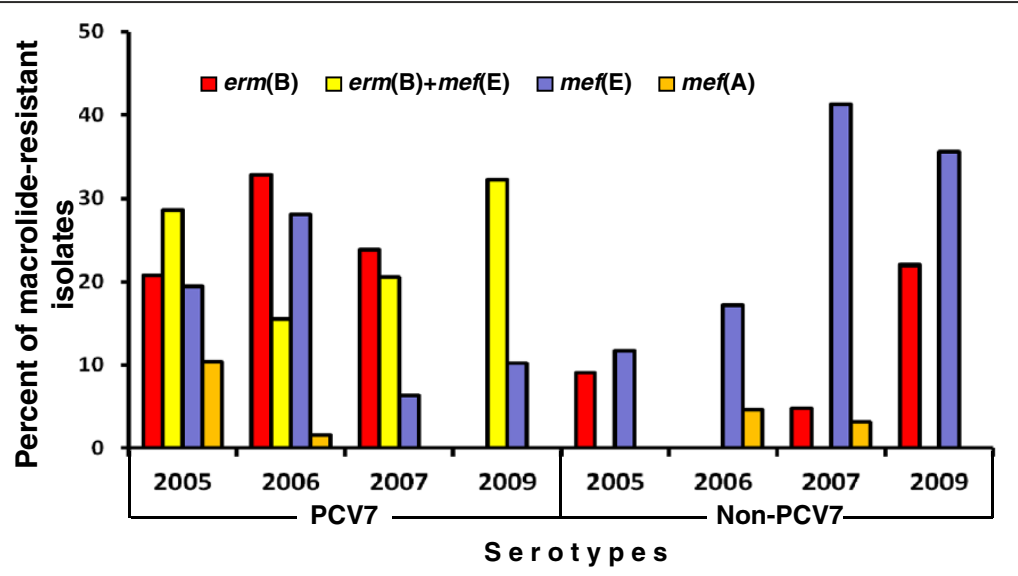

Figure 3 Frequencies of macrolide resistance determinants among isolates belonging to PCV7 and non-PCV7 serotypes according to the year of surveillance. 


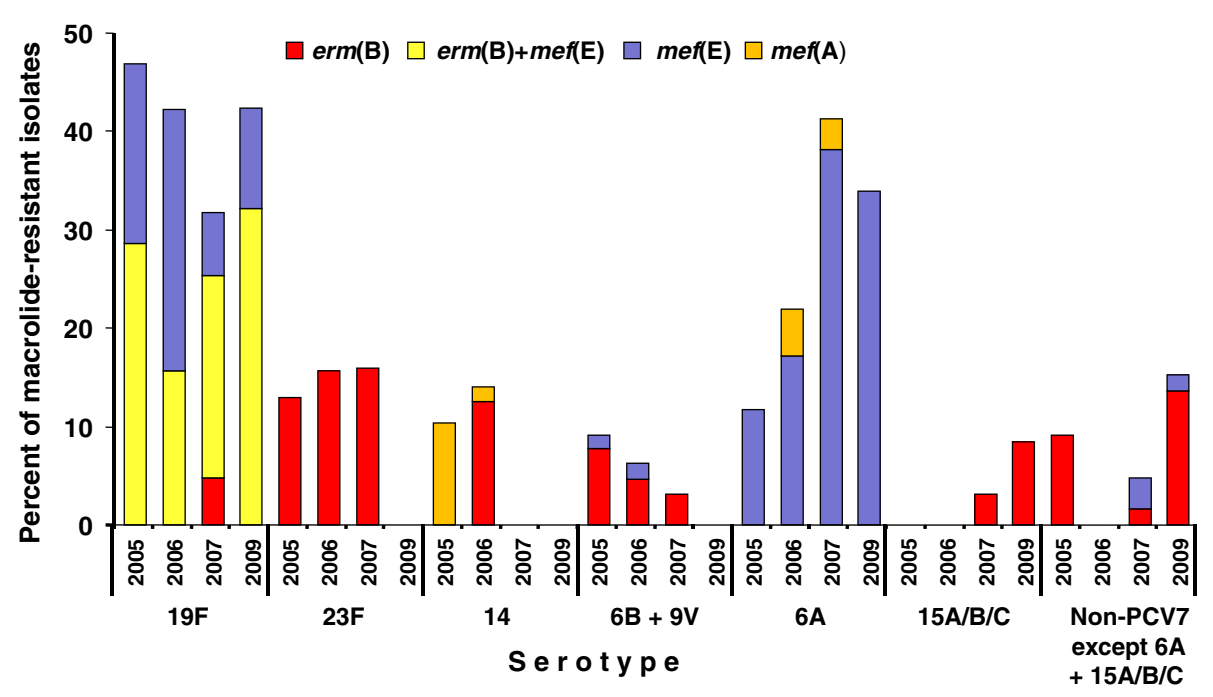

Figure 4 Serotype specific macrolide resistance determinants according to the year of surveillance.

(MICs $1-2 \mu \mathrm{g} / \mathrm{ml} ; \mathrm{MIC}_{90}=2 \mu \mathrm{g} / \mathrm{ml}$ ) were found in the 2006 surveillance in 3 day-care centers. Finally, isolates carrying either $m e f(\mathrm{E})$ or $m e f(\mathrm{~A})$ expressed five different resistance patterns.

Fourteen macrolide-resistant isolates had an MIC to penicillin of $4 \mu \mathrm{g} / \mathrm{ml} ; 12(18.8 \%)$ of the 64 isolates with $\operatorname{erm}(\mathrm{B})+m e f(\mathrm{E})$ and $2(1.8 \%)$ of the 110 mef(E)-positive pneumococci (Table 3).

Of the 265 macrolide-resistant pneumococcal isolates, 188 were tested with levofloxacin and all of them were found to be susceptible (MICs $0.25-1 \mu \mathrm{g} / \mathrm{ml} ; \mathrm{MIC}_{50}=$ $\left.0.5 \mu \mathrm{g} / \mathrm{ml} ; \mathrm{MIC}_{90}=1 \mu \mathrm{g} / \mathrm{ml}\right)$. Among the remainder 77 isolates tested with ciprofloxacin, we did not identify any ciprofloxacin-resistant isolates. These 77 pneumococci had ciprofloxacin MICs from 0.25 to $1 \mu \mathrm{g} / \mathrm{ml}\left(\mathrm{MIC}_{50}=\right.$ $\left.1 \mu \mathrm{g} / \mathrm{ml} ; \mathrm{MIC}_{90}=1 \mu \mathrm{g} / \mathrm{ml}\right)$.

\section{Discussion}

In Greece, an increase in the rate of macrolide resistance among S. pneumoniae occurred after the introduction of newer macrolides in the 1990s and their extensive use thereafter. We have published the phenotypical and molecular analysis of the macrolide-resistant pneumococci recovered from young carriers in different geographic locations of Greece between 1995 and 1999 [32,38,39]. The overall rate of macrolide-resistant S. pneumoniae nasopharyngeal isolates was $18 \%$, while these isolates belonged mainly to serotypes 23F, 6B, 19F, and 14 (in order of

Table 3 Co-resistance among macrolide-resistant isolates of Streptococcus pneumoniae, 2005-2009

\begin{tabular}{|c|c|c|c|c|c|c|c|}
\hline \multirow[t]{3}{*}{ Antibiotic nonsusceptibility } & \multirow{2}{*}{\multicolumn{2}{|c|}{$\begin{array}{l}\operatorname{erm}(B) \\
(n=75)\end{array}$}} & \multirow{2}{*}{\multicolumn{2}{|c|}{$\begin{array}{c}\operatorname{erm}(B)+m e f(E) \\
(n=64)\end{array}$}} & \multirow{2}{*}{\multicolumn{2}{|c|}{$\begin{array}{c}\operatorname{mef}(\mathrm{E}) \\
(\mathrm{n}=110)\end{array}$}} & \multirow{3}{*}{$\begin{array}{c}\operatorname{mef}(\mathrm{A}) \\
(\mathrm{n}=14) \\
\text { CLSI/EUCAST }\end{array}$} \\
\hline & & & & & & & \\
\hline & CLSI & EUCAST & CLSI & EUCAST & CLSI & EUCAST & \\
\hline \multicolumn{8}{|l|}{ Penicillin-nonsusceptible } \\
\hline $\mathrm{MIC}_{50 / 90}(\mathrm{MIC}$ range) & \multicolumn{2}{|c|}{$1 / 2(0.125-2)$} & \multicolumn{2}{|c|}{$2 / 4(0.25-4)$} & \multicolumn{2}{|c|}{$0.25 / 2(0.125-4)$} & \\
\hline Intermediate & $43(57.3)^{\mathrm{a}, \mathrm{b}}$ & $58(77.3)^{c}$ & $21(32.8)$ & $52(81.2)$ & $85(77.3)$ & $105(95.5)$ & 0 \\
\hline Resistant & $15(20)$ & 0 & $43(67.2)$ & $12(18.8)$ & $22(20)$ & $2(1.8)$ & 0 \\
\hline Clindamycin & $75(100)$ & $75(100)$ & $64(100)$ & $64(100)$ & 0 & 0 & 0 \\
\hline Tetracycline & $55(73.3)$ & $55(73.3)$ & $63(98.4)$ & $63(98.4)$ & $40(36.4)$ & $40(36.4)$ & 0 \\
\hline Chloramphenicol & $41(54.7)$ & $41(54.7)$ & $1(1.6)$ & $1(1.6)$ & 0 & 0 & 0 \\
\hline TMP-SMZ & $62(82.7)$ & $61(81.3)$ & $64(100)$ & $64(100)$ & $48(43.6)$ & $45(40.9)$ & 0 \\
\hline MDR & $74(98.7)$ & $73(97.3)$ & $64(100)$ & $64(100)$ & $48(43.6)$ & $46(41.8)$ & 0 \\
\hline
\end{tabular}

${ }^{a}$ Number in parentheses is percent, unless otherwise indicated.

${ }^{b}$ Oral penicillin $\mathrm{V}$ breakpoints.

'Benzylpenicillin breakpoints (infections other than meningitis).

TMP-SMZ: trimethoprim-sulfamethoxazole; MDR: multidrug-resistant. 
decreasing frequency). Subsequently, studies on clinical as well as colonizing isolates from Greece [R] have reported significantly higher rates of macrolide resistance (up to $\sim 50 \%$ ) than that found in our initial studies $[28,29,40]$. The highest rate of macrolide resistance has been reported in pneumococci recovered from children with non-invasive infections, particularly acute otitis media [28].

Across the 4 surveillance periods of the present study and in parallel to an increase in the number of children who were immunized with PCV7, the frequency of the macrolide-resistant isolates did not change significantly. Overall, 24\% of the typeable S. pneumoniae isolates were macrolide-resistant. This result is in line with a study on carriage among day-care attendees in Lisbon [41]. However, in 2009 a major shift in the serotype distribution of macrolide-resistant isolates occurred. Macrolide-resistant isolates of non-PCV7 serotypes replaced those belonging to PCV7 ones. This shift is in accordance with a recent French study [7]. Vaccination against 7 serotypes of $S$. pneumoniae has led to the near extinction of vaccine serotypes in both asymptomatic carriage and disease $[7,11,41]$. In carriage, vaccine serotypes have been replaced by nonvaccine serotypes. Clonal expansion and/or serotype switching contribute to this replacement [42].

Overall, more than half (52.9\%) of our macrolideresistant isolates possessed $\operatorname{erm}(\mathrm{B})$ either alone or in combination with mef(E). A significant association was found between PCV7 serotypes and the presence of erm (B), either alone or in combination with mef(E) on the one hand and non-PCV7 serotypes and a mef gene as the sole resistance determinant on the other. Among pneumoccoci harboring a mef gene as the sole resistance determinant, the ratio of $m e f(\mathrm{E})$ - to $m e f(\mathrm{~A})$-positive isolates was 7.9:1. This ratio was significantly reversed from the one that we observed among carriers during 1995-1999, which was 1:2.3 [39], and the 1:5 ratio reported from Germany during 2005-2006 [23].

As an overall concept, drug efflux mediated by mef genes has been the most common mechanism in strains of $S$. pneumoniae in North America, whereas in most of the European countries and the Far East, the prevalent mechanism has been rRNA methylation encoded by erm (B) [9]. Nevertheless, this pattern of macrolide resistance determinants is not static and may be changing due to clonal spread of S. pneumoniae of certain serotypes and horizontal transfer of mef elements among streptococci $[23,43]$. Actually, in recent papers, mef(A) was the predominant macrolide resistance determinant in Norway (2001-2005) [44] and Germany (2005-2006) [23], whereas increased frequency of $\mathrm{erm}(\mathrm{B})$ as well as of the dual combination was found in the United States (2005-2008) [13,45].

In the pre-PCV7 period, pneumococci of serotype 14 contributed significantly to macrolide resistance. Among children, serotype 14 had a higher frequency in invasive disease than observed in carriage and non-invasive disease [28]. We have previously reported the circulation of mef(A)-positive macrolide-resistant, penicillin-susceptible serotype 14 isolates with a genotype identical to the international clone England-9 ${ }^{14}$ among young carriers in Greece [39]. Similar isolates continued to circulate in our area during the first 2 years of the present study. In addition, in 2006 we found macrolide-resistant serotype 14 isolates possessing erm(B) and exhibiting penicillinnonsusceptibility. Following the immunization with PCV7, a rapid decrease in the circulation of serotype 14 was noted and it is no longer a major macrolide-resistant serotype in Greece as well as in other countries [46,47].

This study reports a high frequency of serotype 19F pneumococci with both $\operatorname{erm}(\mathrm{B})$ and mef(E) recovered from carriers in several day-care centers in Central Greece across all sampling periods. Since 2001, isolates with the dual resistance mechanism have been increasingly reported from many parts of the world [13,23,45,48-50]. They have mainly been isolated from carriers or patients with non-invasive disease, particularly acute otitis media $[45,50]$. Worldwide, most isolates with the dual resistance mechanism belong to serotypes $19 \mathrm{~F}$ or 19A $[45,48]$. Although serotype $19 \mathrm{~F}$ is represented in the PCV7 vaccine, it affords low levels of protection against upper respiratory infections such as acute otitis media [51] and has been shown to be the least immunogenic of the vaccine serotypes [52]. Moreover, little evidence shows that 19F provides cross-protection against serotype 19A. In Greece, antibiotic pressure may have also contributed to the persistence of these MDR isolates. In our country, isolates with the dual resistance mechanism in a low frequency were identified for the first time among carriers in Athens during 2003 [29]. In the present study, which differentiated between mef(A) subclasses mef(A) and $m e f(\mathrm{E})$, only isolates carrying the mef(E) gene, but not mef(A), with $\operatorname{erm}(\mathrm{B})$ were observed, underscoring the different genetic background of mef(E) and mef(A). Our findings are in line with a recent study from the USA [45]. S. pneumoniae isolates possessing the mef(A) subclass mef(A) gene, carried on transposon Tn1207.1, in combination with $\operatorname{erm}(\mathrm{B})$ have been described in a paper from Australia [53].

\section{Conclusions}

From 2005 to 2009, the annual rate of macrolideresistant colonizing isolates did not change significantly. Overall, more than half (52.9\%) of the macrolideresistant isolates harbored the $\operatorname{erm}(\mathrm{B})$ gene either alone or in combination with mef(E). Multidrug resistance was significantly more common among the $S$. pneumoniae isolates carrying $\operatorname{erm}(\mathrm{B})$ than among those possessing the $m e f(\mathrm{E})$ gene as the single macrolide resistance determinant. 
Across the 4 sampling periods, the circulation of isolates possessing the mef(A) gene gradually disappeared. Marked changes were observed in the most recent surveillance, as the PCV7 coverage increased. In 2009, a shift to macrolide-resistant pneumoccoci belonging to non-PCV7 serotypes was noted. Serotypes 6A, 19A, 15A, and 15B/C accounted for $54.1 \%$ of macrolide-resistant pneumoccoci. Further trends in the carriage of macrolide resistance determinants among pneumococci belonging to nonPCV7 serotypes in the post-PCV7 period remain to be addressed by future surveillance studies.

\section{Competing interests}

The authors declare that they have no competing interests.

\section{Authors' contributions}

ING was responsible for the bacteriological and molecular analyses. AS and EN participated in the laboratory analyses. DCC and AGT participated in the data analysis. GAS conceived the study and performed the data analysis. ING and GAS drafted the manuscript. AS, EN, DCC and AGT helped to draft the manuscript. All the authors read and approved the final manuscript.

\section{Acknowledgements}

We thank Dr. Elias Zintzaras for performing the statistical analysis. The study was partially supported by a grant from Pfizer, as an investigator initiated project, and the 3089 grant from the Research Committee of the University of Thessaly.

Received: 19 January 2012 Accepted: 1 October 2012

Published: 11 October 2012

\section{References}

1. Klein JO: The epidemiology of pneumococcal disease in infants and children. Rev Infect Dis 1981, 3:246-253.

2. Gray BM, Converse GM 3rd, Dillon HC Jr: Epidemiologic studies of Streptococcus pneumoniae in infants: acquisition, carriage, and infection during the first 24 months of life. J Infect Dis 1980, 142:923-933.

3. Faden H, Duffy L, Wasielewski R, Wolf J, Krystofik D, Tung Y, Tonawanda/ Williamsville Pediatrics: Relationship between nasopharyngeal colonization and the development of otitis media in children. $J$ Infect Dis 1997, 175:1440-1445.

4. Bogaert D, De Groot R, Hermans PW: Streptococcus pneumoniae colonisation: the key to pneumococcal disease. Lancet Infect Dis 2004, 4:144-154.

5. Lin TY, Shah NK, Brooks D, Garcia CS: Summary of invasive pneumococcal disease burden among children in the Asia-Pacific region. Vaccine 2010, 28:7589-7605.

6. Dagan R, Givon-Lavi N, Zamir O, Fraser D: Effect of a nonavalent conjugate vaccine on carriage of antibiotic-resistant Streptococcus pneumoniae in day-care centers. Pediatr Infect Dis J 2003, 22:532-540.

7. Cohen R, Levy C, Bonnet E, Grondin S, Desvignes V, Lecuyer A, Fritzell B, Varon E: Dynamic of pneumococcal nasopharyngeal carriage in children with acute otitis media following PCV7 introduction in France. Vaccine 2010, 28:6114-6121.

8. Grivea IN, Tsantouli AG, Michoula AN, Syrogiannopoulos GA: Dynamics of Streptococcus pneumoniae nasopharyngeal carriage with high heptavalent pneumococcal conjugate vaccine coverage in Central Greece. Vaccine 2011, 29:8882-8887.

9. Farrell DJ, Morrissey I, Bakker S, Felmingham D: Molecular characterization of macrolide resistance mechanisms among Streptococcus pneumoniae and Streptococcus pyogenes isolated from the PROTEKT 1999-2000 study. J Antimicrob Chemother 2002, 50(Suppl. S1):39-47.

10. Van Eldere J, Meekers E, Lagrou K, Massonet C, Canu A, Devenyns I, Verhaegen J, Syrogiannopoulos G, Leclercq R: Macrolide resistance mechanisms in Streptococcus pneumoniae isolates from Belgium. Clin Microbiol Infect 2005, 11:332-334.

11. Jacobs MR, Good CE, Beall B, Bajaksouzian S, Windau AR, Whitney CG: Changes in serotypes and antimicrobial susceptibility of invasive
Streptococcus pneumoniae strains in Cleveland: a quarter century of experience. J Clin Microbiol 2008, 46:982-990.

12. Farrell DJ, Couturier C, Hryniewicz W: Distribution and antibacterial susceptibility of macrolide resistance genotypes in Streptococcus pneumoniae: PROTEKT Year 5 (2003-2004). Int J Antimicrob Agents 2008, 31:245-249.

13. Jenkins SG, Farrell DJ: Increase in pneumococcus macrolide resistance, United States. Emerg Infect Dis 2009, 15:1260-1264.

14. Imöhl M, Reinert RR, Mutscher C, van der Linden M: Macrolide susceptibility and serotype specific macrolide resistance of invasive isolates of Streptococcus pneumoniae in Germany from 1992 to 2008. BMC Microbiol 2010, 10:299

15. Leclercq R, Courvalin P: Resistance to macrolides and related antibiotics in Streptococcus pneumoniae. Antimicrob Agents Chemother 2002, 46:2727-2734

16. Weisblum B: Erythromycin resistance by ribosome modification. Antimicrob Agents Chemother 1995, 39:577-585.

17. Ambrose KD, Nisbet R, Stephens DS: Macrolide efflux in Streptococcus pneumoniae is mediated by a dual efflux pump ( $m e l$ and mef) and is erythromycin inducible. Antimicrob Agents Chemother 2005, 49:4203-4209.

18. Sutcliffe J, Tait-Kamradt A, Wondrack L: Streptococcus pneumoniae and Streptococcus pyogenes resistant to macrolides but sensitive to clindamycin: a common resistance pattern mediated by an efflux system. Antimicrob Agents Chemother 1996, 40:1817-1824.

19. Tait-Kamradt A, Clancy J, Cronan M, Dib-Hajj F, Wondrack L, Yuan W, Sutcliffe J: mefE is necessary for the erythromycin-resistant $M$ phenotype in Streptococcus pneumoniae. Antimicrob Agents Chemother 1997, 41:2251-2255

20. Roberts MC, Sutcliffe J, Courvalin P, Jensen LB, Rood J, Seppala H: Nomenclature for macrolide and macrolide-lincosamide-streptogramin B resistance determinants. Antimicrob Agents Chemother 1999, 43:2823-2830.

21. Oster P, Zanchi A, Cresti S, Lattanzi M, Montagnani F, Cellesi C, Rossolini GM: Patterns of macrolide resistance determinants among communityacquired Streptococcus pneumoniae isolates over a 5-year period of decreased macrolide susceptibility rates. Antimicrob Agents Chemother 1999, 43:2510-2512.

22. Del Grosso M, lannelli F, Messina C, Santagati M, Petrosillo N, Stefani S, Pozzi $\mathrm{G}$, Pantosti A: Macrolide efflux genes $\operatorname{mef}(\mathrm{A})$ and $\operatorname{mef}(\mathrm{E})$ are carried by different genetic elements in Streptococcus pneumoniae. J Clin Microbiol 2002, 40:774-778.

23. Bley $C$, van der Linden $M$, Reinert RR: mef(A) is the predominant macrolide resistance determinant in Streptococcus pneumoniae and Streptococcus pyogenes in Germany. Int I Antimicrob Agents 2011, 37:425-431.

24. Santagati M, lannelli F, Oggioni MR, Stefani S, Pozzi G: Characterization of a genetic element carrying the macrolide efflux gene $\operatorname{mef}(\mathrm{A})$ in Streptococcus pneumoniae. Antimicrob Agents Chemother 2000, 44:2585-2587

25. Santagati M, lannelli F, Cascone C, Campanile F, Oggioni MR, Stefani S, Pozzi G: The novel conjugative transposon Tn1207.3 carries the macrolide efflux gene mef(A) in Streptococcus pyogenes. Microb Drug Resist 2003, 9:243-247.

26. Del Grosso M, Camilli R, lannelli F, Pozzi G, Pantosti A: The mef(E)-carrying genetic element (mega) of Streptococcus pneumoniae: insertion sites and association with other genetic elements. Antimicrob Agents Chemother 2006, 50:3361-3366.

27. Varaldo PE, Montanari MP, Giovanetti E: Genetic elements responsible for erythromycin resistance in streptococci. Antimicrob Agents Chemother 2009, 53:343-353.

28. Paraskakis I, Kafetzis DA, Chrisakis A, Papavasilliou H, Kirikou H, Pangalis A, Tzouvelekis LS, Athanasiou T, Legakis NJ on behalf of the National Surveillance Network for Pneumococcal Resistance: Serotypes and antimicrobial susceptibilities of 1033 pneumococci isolated from children in Greece during 2001-2004. Clin Microbiol Infect 2006, 12:490-493.

29. Souli M, Volonakis K, Kapaskelis A, Galani I, Grammelis V, Vorou R, Tsivra M, Chryssouli Z, Katsala D, Giamarellou H: Characterisation of macrolide-non-susceptible Streptococcus pneumoniae colonising children attending day-care centres in Athens, Greece during 2000 and 2003. Clin Microbiol Infect 2007, 13:70-77.

30. Grivea IN, Tsantouli AG, Chryssanthopoulou DC, Syrogiannopoulos GA: Interaction of the heptavalent pneumococcal conjugate vaccine and the 
use of individual antibiotics among children on nasopharyngeal colonization with erythromycin-resistant Streptococcus pneumoniae. Eur J Clin Microbiol Infect Dis 2010, 29:97-105.

31. Hellenic National Committee for Immunization Programs: National Immunization Program. Paediatriki 2006, 69:78-82.

32. Syrogiannopoulos GA, Grivea IN, Davies TA, Katopodis GD, Appelbaum PC, Beratis NG: Antimicrobial use and colonization with erythromycin-resistant Streptococcus pneumoniae in Greece during the first 2 years of life. Clin Infect Dis 2000, 31:887-893.

33. Clinical and Laboratory Standards Institute (CLSI): Performance Standards for Antimicrobial Susceptibility Testing; Eighteenth Informational Supplement. CLSI document M100-S18. Wayne, PA: CLSl; 2008.

34. European Committee on Antimicrobial Testing (EUCAST): Breakpoints tables for interpretation of MICs and zone diameters. Version 2.0 2012. http://www. eucast.org/fileadmin/src/media/PDFs/EUCAST_files/Breakpoint_tables/ Breakpoint_table_v_2.0_120221.pdf.

35. Sutcliffe J, Grebe T, Tait-Kamradt A, Wondrack L: Detection of erythromycin-resistant determinants by PCR. Antimicrob Agents Chemother 1996, 40:2562-2566

36. Reinert RR, Lütticken R, Bryskier A, Al-Lahham A: Macrolide-resistant Streptococcus pneumoniae and Streptococcus pyogenes in the pediatric population in Germany during 2000-2001. Antimicrob Agents Chemother 2003, 47:489-493.

37. American Academy of Pediatrics: Pneumococcal infections. In Red Book: 2009 Report of the Committee on Infectious Diseases. 28th edition. Edited by Pickering LK, Baker CJ, Kimberlin DW, Long SS. Elk Grove Village, IL: American Academy of Pediatrics; 2009:524-535.

38. Syrogiannopoulos GA, Grivea IN, Beratis NG, Spiliopoulou AE, Fasola EL, Bajaksouzian S, Appelbaum PC, Jacobs MR: Resistance patterns of Streptococcus pneumoniae from carriers attending day-care centers in Southwestern Greece. Clin Infect Dis 1997, 25:188-194.

39. Bogaert D, Hermans PWM, Grivea IN, Katopodis G, Mitchell TJ, Sluijter M, de Groot R, Beratis NG, Syrogiannopoulos GA: Molecular epidemiology of penicillin-susceptible non- $\beta$-lactam-resistant Streptococcus pneumoniae isolates from Greek children. J Clin Microbiol 2003, 41:5633-5639.

40. Maraki S, Samonis G, Galanakis E: Serotypes and susceptibilities of paediatric clinical isolates of Streptococcus pneumoniae in Crete, Greece, before and after the heptavalent pneumococcal conjugate vaccine. Eur J Clin Microbiol Infect Dis 2010, 29:1449-1451.

41. Sá-Leão R, Nunes S, Brito-Avô A, Frazão N, Simões AS, Crisóstomo MI, Paulo ACS, Saldanha J, Santos-Sanches I, de Lencastre H: Changes in pneumococcal serotypes and antibiotypes carried by vaccinated and unvaccinated day-care centre attendees in Portugal, a country with widespread use of the seven-valent pneumococcal conjugate vaccine. Clin Microbiol Infect 2009, 15:1002-1007.

42. Hanage WP, Bishop CJ, Huang SS, Stevenson AE, Pelton SI, Lipsitch M, Finkelstein JA: Carried pneumococci in Massachusetts children. The contribution of clonal expansion and serotype switching. Pediatr Infect Dis J 2011, 30:302-308.

43. Ardanuy C, Fenoll A, Berrón S, Calatayud L, Liñares J, and the Spanish Pneumococcal Infection Study Network: Increase of the M phenotype among erythromycin-resistant Streptococcus pneumoniae isolates from Spain related to the serotype 14 variant of the Spain $^{9 \mathrm{~V}}-3$ clone. Antimicrob Agents Chemother 2006, 50:3162-3165.

44. Sogstad MK, Littauer P, Aaberge IS, Caugant DA, Høiby A: Rapid spread in Norway of an erythromycin-resistant pneumococcal clone, despite low usage of macrolides. Microb Drug Resist 2007, 13:29-36.

45. Bowers JR, Driebe EM, Nibecker JL, Wojack BR, Sarovich DS, Wong AH, Brzoska PM, Hubert N, Knadler A, Watson LM, Wagner DM, Furtado MR, Saubolle M, Engelthaler DM, Keim PS: Dominance of multidrug resistant CC271 clones in macrolide-resistant Streptococcus pneumoniae in Arizona. BMC Microbiol 2012, 12:12

46. Aguiar SI, Brito MJ, Gonçalo-Marques J, Melo-Cristino J, Ramirez M: Serotypes 1,7F and 19A became the leading causes of pediatric invasive pneumococcal infections in Portugal after 7 years of heptavalent conjugate vaccine use. Vaccine 2010, 28:5167-5173.

47. Rückinger S, van der Linden M, Reinert RR, von Kries R, Burckhardt F, Siedler $A$ : Reduction in the incidence of invasive pneumococcal disease after general vaccination with 7-valent pneumococcal conjugate vaccine in Germany. Vaccine 2009, 27:4136-4141.
48. McGee L, Klugman KP, Wasas A, Capper T, Brink A, and the Antibiotics Surveillance Forum of South Africa: Serotype 19F multiresistant pneumococcal clone harboring two erythromycin resistance determinants $[\operatorname{erm}(\mathrm{B})$ and mef(A)] in South Africa. Antimicrob Agents Chemother 2001, 45:1595-1598.

49. Farrell DJ, Morrissey I, Bakker S, Morris L, Buckridge S, Felmingham D: Molecular epidemiology of multiresistant Streptococcus pneumoniae with both $\operatorname{erm}(\mathrm{B})$ and mef(A)-mediated macrolide resistance. J Clin Microbiol 2004, 42:764-768.

50. Farrell DJ, Jenkins SG, Brown SD, Patel M, Lavin BS, Klugman KP: Emergence and spread of Streptococcus pneumoniae with erm(B) and mef(A) resistance. Emerg Infect Dis 2005, 11:851-858.

51. Eskola J, Kilpi T, Palmu A, Jokinen J, Haapakoski J, Herva E, Takala A, Käyhty H, Karma P, Kohberger R, Siber G, Mäkela PH: Efficacy of a pneumococcal conjugate vaccine against acute otitis media. N Engl J Med 2001, 344:403-409.

52. Ekström N, Åhman $H$, Verho J, Jokinen J, Väkeväinen M, Kilpi T, Käyhty H: Kinetics and avidity of antibodies evoked by heptavalent pneumococcal vaccines PncCRM and PncOMPC in the Finnish otitis media vaccine trial. Infect Immun 2005, 73:369-377.

53. Xu X, Cai L, Xiao M, Kong F, Oftadeh S, Zhou F, Gilbert GL: Distribution of serotypes, genotypes, and resistance determinants among macrolide-resistant Streptococcus pneumoniae isolates. Antimicrob Agents Chemother 2010, 54:1152-1159.

doi:10.1186/1471-2334-12-255

Cite this article as: Grivea et al:: Macrolide resistance determinants among Streptococcus pneumoniae isolates from carriers in Central Greece. BMC Infectious Diseases 2012 12:255.

\section{Submit your next manuscript to BioMed Central and take full advantage of:}

- Convenient online submission

- Thorough peer review

- No space constraints or color figure charges

- Immediate publication on acceptance

- Inclusion in PubMed, CAS, Scopus and Google Scholar

- Research which is freely available for redistribution 